\title{
Impact of Dietary Pattern Application on the Nutritional Status of Adolescents with Leukemia Undergoing Chemotherapy
}

\author{
Emad Ghassan Eshak, Assistant Lecturer \\ Pediatric Nursing, Faculty of Nursing, Tishreen University, Syria.
}

\author{
Gamalat El-Sayed Mansy, Professor \\ Pediatric Nursing, Faculty of Nursing, Alexandria University.
}

Ekram Mohammed Hemly, Professor

Pediatric Medicine, Faculty of Medicine, Alexandria University.

Yousr Abdel Salam Jaafar, Professor

Pediatric Nursing, Faculty of Nursing, Alexandria University.

\author{
Hanan Fawzi Nazir, Professor \\ Pediatric Medicine, Faculty of Medicine, Alexandria University.
}

\begin{abstract}
Leukemia is the commonest neoplastic disease of infancy and childhood, accounting for $30-45 \%$ of all childhood concerns worldwide. Malnutrition in pediatric oncology population has been reported to occur in $32 \%$ of patients in USA and in $50 \%$ of patients in Netherlands. Unlike adults, childrens` nutritional needs must include energy requirement for growth and development. In addition, those needs are required to support the child during the disease and its treatment. Pediatric nurses are part of the nutrition team in all pediatric units. They have an important role in identifying whether children are at risk or actually have malnutrition. Objective: To assess the nutritional status of adolescents with leukemia and determine the impact of application of dietary pattern on nutritional status of adolescents with leukemia undergoing chemotherapy. Setting: The study was conducted in the University Childrens Hospital and Sporting Students`Hospital in Alexandria. Subjects: A convenient sample of 60 adolescents with leukemia was included in the study. Tools: Data was collected by using three tools. Adolescents and their care givers were interviewed to collect socio-demographic data and medical history of the disease. The subjects were undergone a comprehensive nutritional assessment and application of dietary pattern. Data was collected during a period of 8 months. Results: The results showed that application of dietary pattern during chemotherapy was significantly effective in improving the adolescents' nutritional style, adolescents`knowledge about their proper nutrition during chemotherapy, the chemotherapy side effects and their management. It also showed improvement in the leukemic adolescents anthropometric measurements and laboratory investigations. Conclusion: Application of a dietary pattern during chemotherapy was significantly effective in improving the adolescents' nutritional style, their knowledge about their proper nutrition, and their treatment. Recommendations: Emphasizing the importance of nutritional assessment and management process in the medical settings are mandatory. Educating and training the nursing staff to be familiar with how and when to apply such process and improving the food service in medical setting are highly recommended.
\end{abstract}




\section{Introduction}

Leukemia is the commonest neoplastic disease of infancy and childhood, accounting for $30-45 \%$ of all childhood cancers worldwide. It is considered the second leading cause of death in developed countries $^{(1-3)}$. According to the Center for Arab Genomic Studies (CAGS), leukemia is one of the 10 most common malignancies and the major form of pediatric cancer in most of Arab countries. With a prevalence rate of 5.1 and 3.7 per 100,000 inhabitants in Egypt and Syria respectively, those two countries are internationally ranked as number 28 and 42 consecutively ${ }^{(4)}$.

Leukemia is considered one of the diseases that predispose patients to a high nutritional risk $^{(5,6)}$. The intensive chemotherapy used in the treatment of leukemia usually involves using drugs that have significant gastrointestinal toxicity causing nausea, vomiting, diarrhea, anorexia, and mucositis which adversely affect dietary intake. Therefore, ensuring proper nutrition in children is a challenging task with anti-cancer treatments ${ }^{(7-9)}$.

Malnutrition in pediatric oncology population has been reported to occur in $32 \%$ of patients in $\mathrm{USA}^{(7)}$ and in $50 \%$ of patients in Netherlands ${ }^{(8)}$.

Cancer Treatment AssociatedMalnutrition predisposes the child to increased morbidity, decreased immune function, poorer disease outcome, and negatively affects patients' response to therapy and increases the incidence of treatment-related side effects ${ }^{(9,10)}$.

Fundamental to managing the malnutrition problem is to detect it. In-depth nutritional assessment should provide the opportunity to identify malnutrition or patients at high nutritional risk at an early stage of medical care, establish nutritional needs and care plans, and to assess the appropriate route of nutrition. Routine assessment of patients to identify risk of malnutrition has been recommended by many national, international and specialized organizations ${ }^{(11,12)}$.

The child's weight and height are among the simplest anthropometric measures. Moreover, when measured accurately and regularly, weight changes are valuable indicators of nutritional risk. Body Mass Index is an indirect measure of lean body mass and fat stores. In adolescents, BMI for age correlates with total body fatness and can be used as a screening tool to determine over or under-nutrition ${ }^{(13)}$.

Biochemical data, such as visceral protein, glucose levels, hemoglobin (HB), hematocrit (HCT), and lymphocyte count can be used to help estimate nutritional status. In a state of malnutrition, $\mathrm{HB}$ and HCT tend to decrease due to inadequate amounts of protein consumption and possibly iron deficiency, as well as chemotherapy and penetration of malignant cells into the bone marrow ${ }^{(13)}$.

Clinical data obtained from the physical examination of a child with cancer is an integral part of nutritional assessment and should never be omitted. Activity level, presence of edema, changes in skin, face, hair, eyes, and vital signs are among the clinical data that should be considered ${ }^{(13)}$.

Pediatric nurses have an important role in identifying whether children are at risk or actually have malnutrition and should monitor it and deal with other complicated nutritional problems. According to the American Academy of Pediatrics (AAP) and to the European Society of Pediatric Gastroenterology Hepatology and Nutrition (ESPGHAN) Committee on Nutrition, knowledgeable nurses in oncology protocols and nutrition must be members of a nutrition support team in all pediatric units. Their main tasks should include screening and assessing for nutritional risk, identification of patients who require nutritional support, provision of adequate nutritional management, education and training of hospital staff and primary caregivers on how to identify and manage 
nutritional problems. Nurses help to prevent malnutrition by providing supportive care, encouraging oral hygiene, encouraging oral intake and maintaining accurate intakeoutput records, and caregiver education. They provide patients and family with information on the treatment of side effects that may cause nutritional problems with emphasis on the relationship between nutritional status and clinical outcome ${ }^{(14,15)}$.

\section{Aims of the Study}

The present study aims to:

- Assess the nutritional status of adolescents with leukemia after the remission induction phase of chemotherapy.

- Determine the impact of application of a dietary pattern on the nutritional status of adolescents with leukemia undergoing chemotherapy.

\section{Research Hypothesis:}

Adolescents with leukemia have better nutritional outcome during their chemotherapy after the application of a dietary pattern.

\section{Materials and Method}

\section{Materials}

Design: A quasi-experimental design was followed.

Setting: The study was conducted in the University Children's Hospital at El-Shatby and Sporting Students' Hospital in Alexandria.

Subjects: A convenient sample of 60 adolescents with leukemia in the previously mentioned settings was included in the study. The subjects fulfilled the following inclusion criteria.

- Aged from 12-18 years.

- Post the 1 st induction cycle of chemotherapy.
- Free from any other chronic conditions that affect the adolescent's nutritional status such as Diabetes and kidney failure.

Tools: Three tools were used in this study:

Tool I: Adolescents' Knowledge about Nutritional Needs during Chemotherapy Structured Interview Schedule

The tool was developed by the researcher to assess the Adolescents' knowledge about nutritional needs during chemotherapy. It consists of:

- Part 1:

A- Demographic data such as age, sex.

B- Medical history of the disease such as date of diagnosis, time of starting treatment, number of chemotherapy sessions per month.

- Part 2: Adolescents' knowledge about nutritional requirements during chemotherapy and nutritional patterns of the Adolescents such as likes and dislikes, number of meals per day, snacks...etc.

- Part 3: Chemotherapy Nutritional Side Effects: It assessed the type and frequency of the side effects induced by chemotherapy such as nausea, vomiting, diarrhea, and stomatitis...etc.

Tool II: Twenty-Four Hours Recall Method

It was adopted from Elia M, Stratton R. (2002) (11). It was used by the researcher to determine the quantity and quality of the adolescent's food intake in the last 24 hours.

Tool III: Adolescents' Nutritional Assessment Tool

The tool was developed by the researcher. For the purpose of assessing the adolescents' nutritional status, the following data was collected: 
- Part A: Anthropometric Measurements included the adolescent's weight, height, Body Mass Index (BMI), mid-arm circumference, and skin fold thickness.

- Part B: Biochemical Data included hemoglobin, hematocrit, total serum albumin, total lymphocytic, red blood count, glucose levels, and blood urea.

- Part C: Clinical Data about Adolescents included vital signs, general condition, adolescent's activity level, face, eyes, skin, and gastrointestinal problems.

\section{Method}

The study was accomplished as follow.

1- Necessary approval from the ethical committee of Faculty of Nursing, Alexandria University was secured.

2- Official letters from Faculty of Nursing, Alexandria University were sent to the two hospitals in which the study was conducted to facilitate research implementation.

3- Development of the tools was done after thorough review of literature.

4- Tools were tested for content validity by a jury of five experts in the field (validity $=89 \%)$. Necessary modifications were done.

5- The reliability of the tools was asserted and estimated using Cronbach's coefficient alpha test $(\mathrm{r}=$ 0.89).

6- Verbal consent of the patients and their caregivers sharing in the study was obtained. Every adolescent was informed about the aim of the study. Confidentiality, privacy, anonymity, and the patient's right to withdraw at any time were ensured.

7- A pilot study was carried out on six adolescents with leukemia undergoing chemotherapy and the necessary modifications were done.

8- Adolescents and their caregivers were interviewed individually to collect the sociodemographic data and the medical history of the disease (Tool I).

9- The subjects were undergone a comprehensive nutritional assessment that included.

- Assessing their knowledge about proper nutrition during chemotherapy (Tool I).

- Assessing the chemotherapyrelated nutritional problems in relation to type and frequency (Tool I).

- Assessing the Adolescents' daily intake. The caregivers were asked to report every food or drink in portion sizes that the adolescent took during the last 24 hours to determine the quantity and quality of the adolescent's food intake. Analysis of quantity and quality were performed (Tool II).

- Assessing the adolescents' nutritional status (Tool III): the assessment was done three times at the beginning, in the middle ( 2 months later), and at the end of the study (after another 2 months):

a. Anthropometric Measurements were compared to the National Center for Health Statistics Percentiles for Age and Gender $^{(36)}$.

b. Body Mass Index (BMI) was calculated and recorded.

c. All laboratory investigations were taken from the patients' medical record.

The Dietary Pattern for Adolescents with Leukemia:

It contained information related to leukemia, chemotherapy and its nutritional side effects and how to prevent or manage them. It also included nutritional requirements needed during 
chemotherapy and how to prevent poor nutrition.

\section{Objectives:}

By the end of implementation of the dietary pattern, adolescents were able to:

- List the side effects of chemotherapy that have an effect on the nutritional status.

- Explain how to manage each nutritional problem related to chemotherapy.

- Recognize the signs of poor nutritional status.

- Comprehend the importance of good nutrition during chemotherapy.

Adolescents were divided into six groups. Every group included 10 members. The researcher met every group once a week for one hour for 16 weeks .lectures and discussion were used to teach adolescents about the dietary pattern .A laptop and audio visual materials were used. Booklets were distributed to adolescents. The booklet was about importance of proper nutrition during chemotherapy and what to do for the assessed complications.

\section{Ethical considerations:}

Verbal consent was obtained after explaining the purpose of the study. Privacy was maintained during the process of data collection. Confidentiality of collected data and anonymity were guaranteed.

\section{Statistical Analysis}

After data was collected it was revised, coded and fed to statistical software SPSS version 16. The given graphs were constructed using Microsoft excel software.

All statistical analysis was done using two tailed tests and alpha error of $0.05 \mathrm{P}$ value.

\section{Results}

Part I: The socio-demographic and the medical data of leukemic adolescents:

Half of the studied adolescents were in the age group 11-14 years and the other half was in the age group 15-19 years. Their mean age was $14.7 \pm 2.1$ years. The dominant gender was males $(61.7 \%)$. Nearly half of the adolescents $(43.3 \%)$ were in preparatory school and $31.7 \%$ were in primary school. The secondary school adolescents constituted 25.0\%. Concerning the number of siblings and birth orders $33.3 \%$ of adolescents had one sibling and was the first born. While $18.3 \%$ of them had 3 siblings and $10.0 \%$ were the third born children .More than half of the adolescents $(56.7 \%)$ lived in rural areas.

Concerning chemotherapy stage, $38.3 \%$ of the adolescents were in the maintenance stage of chemotherapy and one third of them $(33.3 \%)$ were in the delay intensification stage while $28.3 \%$ of them were in the consolidation stage. About fourty percent of the adolescents (38.3\%) started their chemotherapy treatment over a month ago and one third of them (33.3\%) started over 4 months ago. On the other hand, only $5 \%$ of them started over 2 months ago. As for the number of chemotherapy sessions per month, $40 \%$ of the leukemic adolescents had 2 sessions per month while $23.3 \%$ had 3 sessions or more.

Part II: Nutritional style of adolescents and their knowledge about nutritional needs before and after the application of the dietary pattern:

Table (1) illustrates percent distribution of nutritional style among the adolescents before and after the application of dietary pattern. It includes number of meals per day, regularity of meals, and snacks between meals.

Before the dietary pattern application, $43.3 \%$ of the adolescents state that they eat only one meal and $43.3 \%$ eat three meals/day. After the application of dietary pattern, none of the adolescents eat one 
meal while more than half of them $(55.0 \%)$ eat 3 meals/day. A statistical significant difference at 0.05 is found $(p=.000)$.

Concerning regularity of meals, only $28.3 \%$ of leukemic adolescents states that they eat 3 meals regularly before the application of the dietary pattern compared to $60 \%$ of them after dietary pattern application. A statistical significant difference at 0.05 is found $(\mathrm{p}=.000)$.

At the beginning of the study, $58.3 \%$ of the leukemic adolescents stated that they have snacks between meals compared to all of them after the application of the dietary pattern. A statistical significant difference at 0.05 is found $(\mathrm{p}=.000)$.

Tables (2-a), (2-b), (2-c) show the percent distribution of the adolescents' knowledge about their nutritional needs during chemotherapy.

In table (2-a), when asking the adolescents about the composition of a good nutrition, three quarters of them $(75 \%)$ didn't know the composition of a good nutrition before the application of dietary pattern. This percentage decreased to zero after the dietary pattern. There is a statistical significant difference at $0.05(\mathrm{p}=.000)$.

At the beginning of the study, only $21.7 \%$ of adolescents know that protein is among the elements of good nutrition compared to $88.3 \%$ after the application of the dietary pattern. The difference is statistically significant at $0.05 \quad(p=0.000)$. Moreover, before the application of the dietary pattern only $3.3 \%$ of adolescents stated that each of carbohydrates and fats are among the elements of good nutrition while after the application more than half $(53.3 \%)$ mention carbohydrates and $18.3 \%$ mention fats. Statistical significant differences are found at $0.05(\mathrm{p}=0.000$ and $\mathrm{p}=0.003$ respectively). Furthermore, $23.3 \%$, and $10 \%$ at the beginning of the study mention that good nutrition should contains vitamins and minerals consecutively. After the application of the dietary pattern $78.3 \%$ and $45 \%$ mention vitamins and minerals respectively. Differences are statistically significant at $0.05(\mathrm{p}=0.000$ and $\mathrm{p}=0.000$ respectively).

None of the adolescents at the beginning of the study know that fluids are among good nutrition while at the end of the study the majority of them (85\%) know. a statistical significant difference at 0.05 is found $(\mathrm{p}=.000)$.

In table (2-b), before the application of the dietary pattern, three quarters of the adolescents (75\%) didn't know the composition of good nutrition, $3.32 \%$ mentioned only one element out of 6 , $13.33 \%$ mentioned two elements and 5\% mentioned three elements. Only $3.33 \%$ of the adolescents mentioned 5 elements out of 6.

After the application of dietary pattern, $15 \%$ of the adolescents mentioned the whole 6 elements of good nutrition comparing to zero before the application. Adolescents who chose $2,3,4$, or 5 elements out of 6 represented $11.7 \%$, $46.7 \%, 18.4 \%$ and 8.4 respectively.

In table (2-c), although all of the adolescents have dietary changes and chemotherapy side effects after they start their chemotherapy treatment, none of them know neither the reasons for these changes nor ways to reduce them at the beginning of the study compared to $88.3 \%$ of each at the end of the study. Statistical significant differences at 0.05 are found $(\mathrm{p}=.000$ and $\mathrm{p}=0.000)$. On the other hand, more than three quarters of the sample $(76.6 \%)$ knows how to manage to reduce these changes after the application of the dietary pattern compared to $5 \%$ before the application of the dietary pattern. There is a statistical significant difference at $0.05(\mathrm{p}=0.000)$.

At the beginning of the study, only $6.7 \%$ of the leukemic adolescents were taught by doctors about nutrition during their treatment course compared to all of them at the end of the study who were taught by the researcher. The difference is statistically significant at $0.05(\mathrm{p}=0.000)$. 
Concerning the daily intake of fluids, $26.7 \%$ of the sample at the beginning of the study knows how much water they should drink compared to $70 \%$ of them at the end of the study. The difference is statistically significant at $0.05(\mathrm{p}=0.000)$.

\section{Part III: Effect of dietary pattern application on the chemotherapy side effects and leukemic adolescents' nutritional status:}

A. Effect of dietary pattern application on the chemotherapy side effects:

Table (3) shows percent distribution of chemotherapy side effects before and after the application of the dietary pattern. All adolescents have vomiting at the beginning of the study as a side effect of the treatment compared to $73.3 \%$ of them after dietary pattern application. The difference is statistically significant at $0.05(\mathrm{p}=.000)$.

Regarding loss of appetite, mouth ulcers, difficulty swallowing, and constipation, $83.3 \%, 63.3 \%, 60 \%$, and $20 \%$ of the adolescents have them consecutively as a side effect at the beginning of the study. At the end of the study $61.7 \%$ have loss of appetite, only $5 \%$ have mouth ulcers, $38.3 \%$ have difficulty in swallowing, and $10 \%$ have constipation. Differences are statistically significant at $0.05 \quad(\mathrm{p}=.001$, $\mathrm{p}=.000, \mathrm{p}=.012, \mathrm{p}=.008$ respectively). On the other hand, although diarrhea percentage is reduced after the application of the dietary pattern but no statistical significant difference is found.

B. Effect of dietary pattern on adolescents' nutritional status which includes caloric intake, anthropometric measurements, laboratory investigations, and general examination:

Table (4) represents comparison between caloric, protein, carbohydrates and fats daily intakes at the beginning and at the end of the study. While the mean caloric daily intake for the sample at the beginning of the study is $629.7 \pm 495.2 \mathrm{kcal}$, the mean caloric intake at the end of the study is
$792.6 \pm 426.2 \mathrm{kcal}$. The difference is statistically significant at $0.05(\mathrm{p}=.005)$.

Concerning mean protein daily intake, before the dietary pattern application is $29.6 \pm 25.7 \mathrm{~g}$. On the other hand this mean increased to $41.6 \pm 28.5 \mathrm{~g}$ after the application. A statistical significant difference is found at $0.05(\mathrm{p}=.000)$.

As for mean carbohydrates daily intake, at the beginning and at the end of study is $80.2 \pm 66.4 \mathrm{~g}$ and $110.8 \pm 70.6 \mathrm{~g}$ respectively. The difference is statistically significant at $0.05(\mathrm{p}=.008)$. Moreover, fats mean daily intake increased from $21.9 \pm 18.5 \mathrm{~g}$ at the beginning of the study to $25.8 \pm 14.4 \mathrm{~g}$ at the end of the study. There is a statistically significant difference at $0.05(\mathrm{p}=.035)$.

Tables (5-a) and (5-b) illustrate the comparison between anthropometric measures of leukemic adolescents at the beginning, after 2 months, and at the end of the study.

As table (5-a) shows, mean weight-forage percentile has increased from $67.52 \pm 24.60$ at the beginning of the study, to $71.11 \pm 23.81$ after 2 months, to $73.16 \pm 23.51$ at the end of the study. Statistically significant differences are found at $0.05(\mathrm{p}=.000)$. On the other hand, there are no changes in the mean height-forage percentile throughout the duration of the study.

Table (5-b) shows the mean BMI of the sample increased from $24.6 \pm 3.1$ at the beginning of the study, to $25.1 \pm 3.1$ after 2 months, to $25.4 \pm 3.5$ at the end of the study. Statistically significant differences are found at $0.05(\mathrm{p}=.000)$.

Mean mid-arm circumference and mean skin fold thickness at the beginning of the study are $25.8 \pm 3.6 \mathrm{~cm}$ and $12.2 \pm 2.8 \mathrm{~mm}$ consecutively. After 2 months these means increased to $26.2 \pm 3.2 \mathrm{~cm}$ and $12.9 \pm 2.7 \mathrm{~mm}$ respectively and at the end of the study means are $26.8 \pm 3.3 \mathrm{~cm}$ for mid-arm circumference and $13.5 \pm 2.7 \mathrm{~mm}$ for skin fold thickness. Differences are statistically 
significant at $0.05(\mathrm{p}=.000$ and $\mathrm{p}=.000$ respectively).

Table (6) presents the comparison between the mean value and SD of some of biochemical data. Concerning the mean value of $\mathrm{Hb}$ levels, they increased from $8.8 \pm 2.7 \mathrm{~g} / \mathrm{dL}$ at the beginning of the study to $9.3 \pm 1.8$ after 2 months to $9.6 \pm 1.7$ at the end of the study. Differences are statistically significant at $0.05(p=.003)$. Furthermore, mean value of Hct levels differences are statistically significant at $0.05 \quad(p=.000)$ when these levels increased from $27.8 \pm 9.6$ at the beginning of the study to $30.7 \pm 6.2$ at the end of the study. On the other hand, although serum albumin levels are increased from $3.0 \pm 0.7$ to $3.1 \pm 0.4$ both after 2 months and at the end of the study, no statistically significant difference is found.

Mean value of $\mathrm{WBC}$ and $\mathrm{RBC}$ at the beginning of the study are $6.6 \times 10^{3} \pm 5.6$ and $2.8 \times 10^{6} \pm 0.6$ respectively. They are increased to $8.7 \times 10^{3} \pm 4.5$ and $3.0 \times 10^{6} \pm 0.6$ consecutively after 2 months and to $9.0 \times 10^{3} \pm 3.0$ and $2.9 \times 10^{6} \pm 0.4$ at the end of the study. Differences are statistically significant at $0.05(\mathrm{p}=.000$ and $\mathrm{p}=.000$ respectively).

An increase in the mean value of serum urea is observed after 2 months of the study $(24.8 \pm 5.5 \mathrm{mg} / \mathrm{dL})$. However it decreased to $22.9 \pm 3.9$ at the end of the study and the difference is statistically significant at 0.05 $(\mathrm{p}=.000)$.

Table (7) represents percent distribution of the adolescents according to physical examination before and after the dietary pattern application. Regarding activity level, adolescents who were not active at the beginning of the study decreased from $21.7 \%$ to merely $3.3 \%$ at the end, whereas semi-active adolescents increased from $28.3 \%$ to $46.7 \%$ after 2 months to $48.3 \%$ at the end of the study. On the other hand, those who were active presented $48.3 \%$ of the sample at the beginning of the study and $46.7 \%$ at the end. Differences are statistically significant at $0.05(\mathrm{p}=.032)$.
Around half of the sample (51.5\%) has a pale face at the beginning of the study. This percentage decreased to $43.6 \%$ after 2 months and to $15 \%$ at the end of the study. A statistically significant differences are found at $0.05(\mathrm{p}=.000)$.

Concerning mouth dryness, a noticeable reduction is observed in those who have mouth dryness from $21.2 \%$ at the beginning to $8.3 \%$ at the end of the study. A statistically significant difference is found at $0.05(\mathrm{p}=.001)$.

One fifth of the adolescents (20\%) has a yellow sclera both at the beginning and after 2 months, whereas it decreases to $8.2 \%$ at the end of the study. There is a statistically significant difference at $0.05(\mathrm{p}=.001)$.

As for conjunctiva, $53.3 \%, 60 \%$, and $16.7 \%$ of the adolescents had a pale conjunctiva at the beginning of the study, after 2 months, and at the end of the study respectively. Differences are statistically significant at $0.05(\mathrm{p}=.000)$.

As regards skin color, $43.3 \%$ of the adolescents have a pale skin at the beginning and decreased to only $15 \%$ at the end of the study. A statistical significant difference is found at $0.05(\mathrm{p}=.000)$.

\section{Discussion}

The socio-demographic and the medical data of leukemic adolescents:

The current study involved 60 leukemic adolescents. About two thirds of them were males, a finding that goes in line with the generally reported higher frequency of cancer among males compared with females ${ }^{(16)}$. Rural areas had higher incidence $(56.7 \%)$ of leukemia than urban areas $(43.3 \%)$ in the present study. However, Rybojad, et al 2013 reported that there were no differences in prevalence and overall survival between rural and urban areas among adults with lung cancer ${ }^{(17)}$.

The current study reported that the less the number of sibling, the higher the incidence of ALL. Bevier, et al 2011 
contradicted the previous results and reported the higher the number of siblings, the higher the incidence of leukemia ${ }^{(18)}$. Concerning birth order, the present study reported decreased incidence of ALL with increased birth order. Many studies have contradicted these results. Bevier, et al 2011 in Germany and Von Behren, 2010 in USA observed increased risk of ALL with increasing birth order ${ }^{(18,19)}$.

\section{Nutritional Style of Leukemic Adolescents and their Knowledge about Nutritional Needs:}

The present study showed a significant increase in the number of meals and its regularity and the number of snacks that were eaten per day by leukemic adolescents after the dietary pattern application. A study conducted by Hernell, et al 2012 had reported a similar finding in children when the number of meals and energy intake showed a $12 \%$ increase after the introduction of new mealtime routines during chemotherapy ${ }^{(20)}$.

There are many symptoms that result from the chemotherapy treatment that can affect the oral intake in children with cancer. The most common symptoms are nausea and vomiting accompanied with anorexia caused by GIT mucosal cells damage due to the cancer chemotherapeutic agents. Furthermore, salivary gland damage and decreased saliva production can result in taste changes and inability to chew and swallow. These side-effects result in decreased oral intake as well as fluid and electrolytes imbalance. Therefore, the low oral intake in the present study can be associated with high percentage of adolescents who suffered from the chemotherapy side effects at the beginning of the study ${ }^{(21)}$.

In the present study, educating and teaching adolescents about their nutritional needs during chemotherapy turned to have an effect on their knowledge about the chemotherapy side effects and ways to manage them. Number of adolescents who didn't know what cause the chemotherapy side effects decreased significantly and the number of them who were able to manage these side effects significantly increased. This finding was documented when studying the efficacy of proactive information on self-care in chemotherapy patients. Patients receiving side effect management information proactively performed significantly higher scores on all of the self-care behavior scale and had fewer side effects than the control group ${ }^{(22)}$. Moore, et al 2004 contradicted this finding ${ }^{(23)}$.

Effect of dietary pattern on the chemotherapy side effects and leukemic adolescents' nutritional status:

In the current study, after the application of the dietary pattern, most of the chemotherapy side effects were significantly reduced except nausea. Vomiting, loss of appetite, and mouth ulcers had a $26.7 \%, 21.6 \%$, and $58.3 \%$ reduction respectively. A small study in adults with prostate cancer found that preventative nutrition counseling which included supplementation and nutritional medical education and management resulted in a statistically significant decrease in therapy delays, hospitalizations, and complications of therapy ${ }^{(24)}$. The same study also found that the intervention group was able to receive more dose-intense therapy.

Although energy, protein, carbohydrates, and fat intakes were significantly increased after the application of the dietary pattern, they are still less than the recommended daily allowance for healthy adolescents suggested by the American Academy of Pediatrics 2009, the Pediatric Nutrition Practice Group 2001, and the American Dietetic Association $1998^{(25)}$. Assessing nutritional status of children with hematological malegnancies, Linga, V et al 2012 reported that $79 \%$ of patients had deficit caloric intake and $74 \%$ of them had deficit protein intake ${ }^{(26)}$. A contradicting result reported by Bond, 1992 who found that the study group energy 
intake was similar to controls groups and was below the recommended dietary allowance (RDA) in both groups ${ }^{(27)}$.

In the present study, the means weightfor-age percentile have shown a significant rise after 2 months of starting the dietary pattern and at the end of the study. Considering the low energy intake of the children in the current study, the means percentiles at the beginning, after 2 months, and at the end of study were ranged between $>50^{\text {th }}$ percentile and $<75^{\text {th }}$ percentile. Weight may further be altered by hydration status during chemotherapy ${ }^{(28)}$. Studying the effect of glucocorticoid therapy on energy intake in children treated for ALL, Reilly, et al 2001 reported that Glucocorticoid treatment in childhood acute lymphoblastic leukemia increases energy intake markedly, and this effect contributes to the excess weight gain and obesity characteristic of patients being treated for acute lymphoblastic leukemia ${ }^{(29)}$.

The other anthropometric measurements in the present study also showed a significant increase after the application of the dietary pattern. Of course BMI value is largely dependent on the weight value of the patient. Moreover, Murphy, 2011 reported that there was no significant difference in the height, weight, and BMI between the children with cancer and the healthy controls when the raw measurements were examined ${ }^{(30)}$.

In the present study, except for the albumin, all laboratory investigation has shown a significant increase after the application of the dietary pattern. One study reported that anemia was one of the most common manifestations in $59 \%$ of children with cancer having $\mathrm{Hb}$ level $<8 \mathrm{gm} / \mathrm{dl}$ and $32 \%$ having $\mathrm{Hb}$ level $8-10 \mathrm{gm} / \mathrm{dl}^{(31)}$. A finding that is similar to the results of the present study. At the beginning of the present study, Blood urea showed lowest grade of normal, then rising after 2 months to drop again at the end of the study. Acute or chronic chemotherapy induced nephrotoxicity may result from the direct effect of the chemotherapy drugs on kidney or on the glomerular distal tubule pathways or indirectly cause renal toxicity by the tumor cells releasing large volumes of ions and metabolites as they die this cellular debris can result in a blockage of the tubes resulting in impaired renal function and toxicity. Non-steroidal anti-inflammatory drugs used to treat cancer pain may cause acute kidney injury in patients with a reduced effective circulating volume ${ }^{(32)}$. A study reported that $55 \%$ of the children had low albumin levels and blood urea was increased beyond the reference value in $37 \%$ of the children ${ }^{(33)}$. Moreover, the nonstatistical slight improvement in the albumin levels might be due to improvement in the protein intake as shown in the results of the present study. However, Huhmann and Cunningham (2005) reported that serum albumin is not a sensitive indicator of nutritional status as it has a 14to 20-day half-life and might be affected by other factors. Therefore, serum albumin doesn't clearly reflect the nutritional status among children with leukemia ${ }^{(34)}$.

Low levels of physical activity, musculoskeletal morbidity are commonly reported problems in children with cancer. In the present study, activity level has significantly improved. Adolescents were encouraged to increase their physical activity explaining the benefit of physical activity on their health and nutritional status. Many studies reported that children with malignancies have a decreased physical activity after starting their chemotherapy treatment ${ }^{(35,36)}$. Moreover, intensive medical treatment and a decline in physical activity in childhood cancer may also result in reduced motor performance later in adulthood ${ }^{(37)}$. A study conducted by Florin et al 2007 reported that long-term survivors of childhood ALL are less likely to meet physical activity recommendations and more likely to report no leisure-time physical activity in the past month ${ }^{(38)}$. 


\section{Conclusion}

The present study concluded that the application of a dietary pattern during chemotherapy was significantly effective in improving the adolescents' nutritional style, their knowledge about their proper nutrition, and their treatment. It also effective in increasing the leukemic adolescents anthropometric measurements, all laboratory investigations except serum albumin and improving general condition.

\section{Recommendations}

- The researcher emphasizes the necessity of nutritional assessment and management throughout their disease and treatment course.

- It is also important to improve the food service and its quality in pediatric medical setting to ensure proper nutrition to cancer patients. 
Table (1): percent distribution of adolescents' nutritional style before and after dietary pattern $(n=60)$.

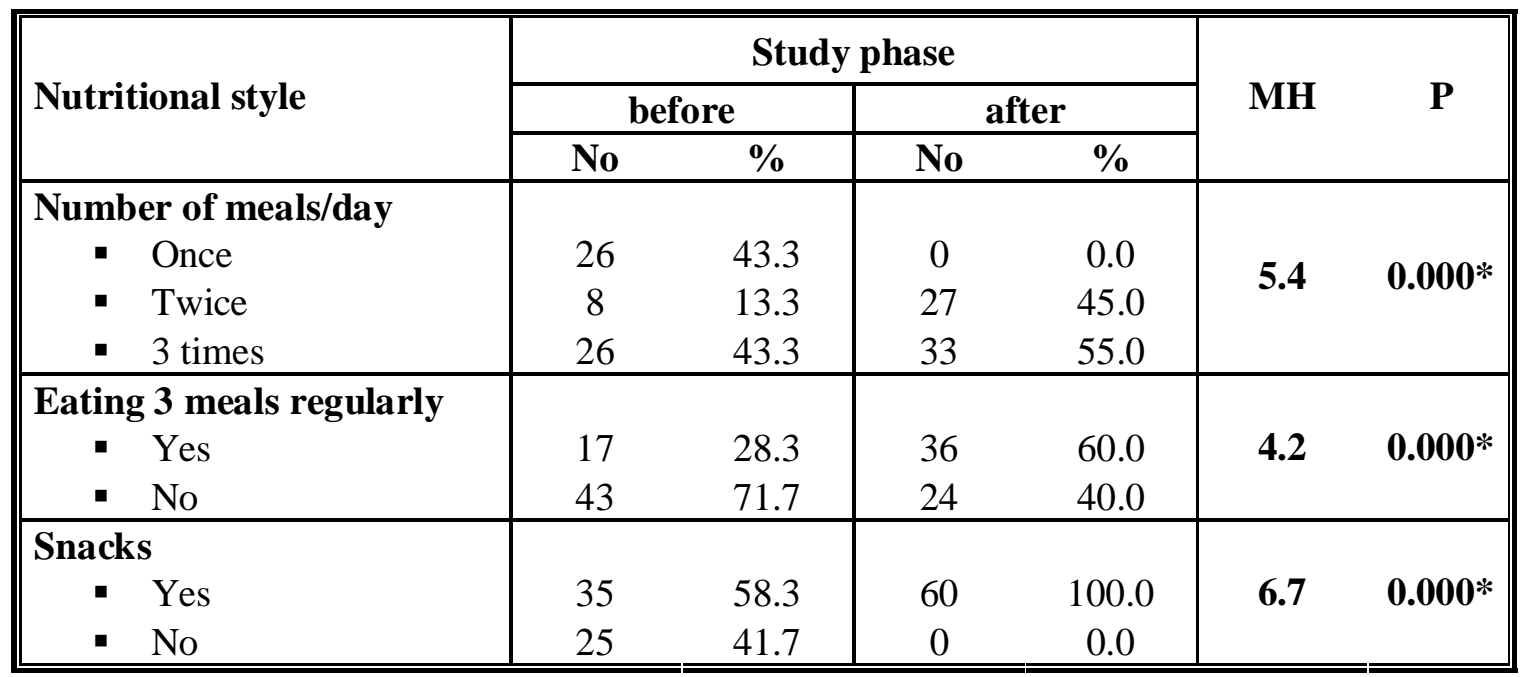

MH: Marginal homogeneity test for two related samples

$* \mathrm{P}<0.05$ (significant)

Table (2-a): percent distribution of adolescents' knowledge about nutritional needs during chemotherapy before and after the dietary pattern application $(n=60)$.

\begin{tabular}{|c|c|c|c|c|c|c|}
\hline \multirow{3}{*}{$\begin{array}{l}\text { Knowledge about nutritional } \\
\text { needs }\end{array}$} & \multicolumn{4}{|c|}{ Study phase } & \multirow{3}{*}{ MH } & \multirow{3}{*}{$\mathbf{P}$} \\
\hline & \multicolumn{2}{|c|}{ before } & \multicolumn{2}{|c|}{ after } & & \\
\hline & No & $\%$ & No & $\%$ & & \\
\hline \multicolumn{7}{|l|}{$\begin{array}{l}\text { Composition of good } \\
\text { nutrition }\end{array}$} \\
\hline - Proteins & 13 & 21.7 & 53 & 88.3 & 6.3 & $0.000 *$ \\
\hline - Carbohydrates & 2 & 3.3 & 32 & 53.3 & 5.4 & $0.000 *$ \\
\hline - Fat & 2 & 3.3 & 11 & 18.3 & 3.0 & $0.003 *$ \\
\hline - Vitamins & 14 & 23.3 & 47 & 78.3 & 5.6 & $0.000 *$ \\
\hline - Minerals & 6 & 10.0 & 27 & 45.0 & 4.6 & $0.000 *$ \\
\hline - Fluids & 0 & 0.0 & 51 & 85.0 & 7.1 & $0.000 *$ \\
\hline - don't know & 45 & 75.0 & 0 & 0.0 & 6.5 & $0.000 *$ \\
\hline
\end{tabular}

MH: Marginal homogeneity test for two related samples

$* \mathrm{P}<0.05$ (significant) 
Table (2-b): percent distribution of adolescents' knowledge about the composition of good nutrition before and after the application of dietary pattern $(n=60)$.

\begin{tabular}{|c|c|c|c|c|}
\hline \multirow{3}{*}{ Compositions of good nutrition } & \multicolumn{4}{|c|}{ Study phase } \\
\hline & \multicolumn{2}{|c|}{ before } & \multicolumn{2}{|c|}{ After } \\
\hline & No & $\%$ & No & $\%$ \\
\hline Don't Know & 45 & 75 & 0 & 0 \\
\hline $\begin{array}{l}\text { Mention } 1 / 6 \text { elements } \\
\text { (protein or vitamins) }\end{array}$ & 2 & 3.32 & 0 & 0 \\
\hline $\begin{array}{l}\text { Mention } 2 / 6 \text { elements } \\
\text { (protein }+ \text { vitamins or protein }+ \\
\text { minerals or vitamins }+ \text { fluids) }\end{array}$ & 8 & 13.33 & 7 & 11.7 \\
\hline $\begin{array}{l}\text { Mention } 3 / 6 \text { elements } \\
\text { (protein }+ \text { vitamins }+ \text { minerals or } \\
\text { protein }+ \text { carbo }+ \text { vitamins or protein }+ \\
\text { carbo }+ \text { fluids or protein }+ \text { vitamins }+ \\
\text { fluids or protein }+ \text { minerals }+ \text { fluids })\end{array}$ & 3 & 5 & 28 & 46.7 \\
\hline $\begin{array}{l}\text { Mention } 4 / 6 \text { elements } \\
\text { (protein }+ \text { carbo + vitamins + minerals } \\
\text { or protein }+ \text { carbo + vitamins }+ \text { fluids or } \\
\text { protein }+ \text { fats }+ \text { minerals }+ \text { fluids })\end{array}$ & 0 & 0 & 11 & 18.4 \\
\hline $\begin{array}{l}\text { Mention } 5 / 6 \text { elements } \\
(\text { protein }+ \text { carbo }+ \text { fat }+ \text { vitamins }+ \\
\text { minerals or protein }+ \text { carbo }+ \text { vitamins }+ \\
\text { minerals }+ \text { fluids })\end{array}$ & 2 & 3.33 & 5 & 8.4 \\
\hline Mention 6/6 elements & 0 & 0 & 9 & 15 \\
\hline
\end{tabular}


Table (2-c): adolescents' knowledge about nutritional needs during chemotherapy before and after the dietary pattern application $(n=60)$.

\begin{tabular}{|c|c|c|c|c|c|c|}
\hline \multirow{3}{*}{$\begin{array}{l}\text { Knowledge about nutritional needs } \\
\text { during chemotherapy }\end{array}$} & \multicolumn{4}{|c|}{ Study phase } & \multirow{3}{*}{ MH } & \multirow{3}{*}{$\mathbf{P}$} \\
\hline & \multicolumn{2}{|c|}{ before } & \multicolumn{2}{|c|}{ After } & & \\
\hline & $\operatorname{No}(60)$ & $\%$ & No(60) & $\%$ & & \\
\hline $\begin{array}{l}\text { Dietary changes after starting } \\
\text { chemotherapy } \\
\text { - Yes } \\
\text { - No }\end{array}$ & $\begin{array}{c}60 \\
0\end{array}$ & $\begin{array}{c}100.0 \\
0.0\end{array}$ & $\begin{array}{c}60 \\
0\end{array}$ & $\begin{array}{c}100.0 \\
0.0\end{array}$ & 0 & 1.000 \\
\hline $\begin{array}{l}\text { Reasons for these changes } \\
\text { - Know } \\
\text { - Do not know }\end{array}$ & $\begin{array}{c}0 \\
60 \\
\end{array}$ & $\begin{array}{c}0.0 \\
100.0 \\
\end{array}$ & $\begin{array}{c}53 \\
7 \\
\end{array}$ & $\begin{array}{l}88.3 \\
11.7 \\
\end{array}$ & 7.3 & $0.000 *$ \\
\hline $\begin{array}{l}\text { ways to reduce side effects } \\
\text { - Know } \\
\text { - Do not know } \\
\end{array}$ & $\begin{array}{c}0 \\
60 \\
\end{array}$ & $\begin{array}{c}0.0 \\
100.0 \\
\end{array}$ & $\begin{array}{c}53 \\
7 \\
\end{array}$ & $\begin{array}{l}88.3 \\
11.7 \\
\end{array}$ & 7.2 & $0.000 *$ \\
\hline $\begin{array}{l}\text { Manage to reduce the side effects } \\
\text { - Know } \\
\text { - Do not know }\end{array}$ & $\begin{array}{c}3 \\
57\end{array}$ & $\begin{array}{c}5.0 \\
95.0\end{array}$ & $\begin{array}{l}46 \\
14\end{array}$ & $\begin{array}{l}76.6 \\
23.3\end{array}$ & 6.9 & $0.000 *$ \\
\hline $\begin{array}{l}\text { Taught about nutrition during } \\
\text { treatment } \\
\text { - Yes } \\
\text { - No } \\
\end{array}$ & $\begin{array}{c}4 \\
56 \\
\end{array}$ & $\begin{array}{r}6.7 \\
93.3 \\
\end{array}$ & $\begin{array}{c}60 \\
0 \\
\end{array}$ & $\begin{array}{c}100.0 \\
0.0\end{array}$ & 7.3 & $0.000 *$ \\
\hline $\begin{array}{l}\text { The daily water intake they should } \\
\text { drink per day } \\
\text { - Know } \\
\text { - Do not know }\end{array}$ & $\begin{array}{l}16 \\
44\end{array}$ & $\begin{array}{l}26.7 \\
73.3\end{array}$ & $\begin{array}{l}42 \\
18\end{array}$ & $\begin{array}{l}70.0 \\
30.0\end{array}$ & 6.8 & $0.000 *$ \\
\hline
\end{tabular}

MH: Marginal homogeneity test for two related samples

$* \mathrm{P}<0.05$ (significant)

Table (3): percent distribution of chemotherapy side effects before and after the application of the dietary pattern $(n=60)$.

\begin{tabular}{|c|c|c|c|c|c|c|}
\hline \multirow{3}{*}{ Side effects of chemotherapy } & \multicolumn{4}{|c|}{ Study phase } & \multirow{3}{*}{ MH } & \multirow{3}{*}{$\mathbf{P}$} \\
\hline & \multicolumn{2}{|c|}{ at beginning } & \multicolumn{2}{|c|}{ at end } & & \\
\hline & No & $\%$ & No & $\%$ & & \\
\hline \multicolumn{7}{|l|}{ Chemotherapy side effects } \\
\hline - Vomiting & 60 & 100.0 & 44 & 73.3 & 4.0 & $0.000 *$ \\
\hline - Nausea & 57 & 95.0 & 60 & 100.0 & 0.24 & 0.250 \\
\hline - Loss of Appetite & 50 & 83.3 & 37 & 61.7 & 3.4 & $0.001 *$ \\
\hline - Mouth ulcers & 38 & 63.3 & 3 & 5.0 & 5.8 & $0.000 *$ \\
\hline - Diarrhea & 37 & 61.7 & 28 & 46.7 & 1.9 & 0.059 \\
\hline - Difficulty swallowing & 36 & 60.0 & 23 & 38.3 & 2.5 & $0.012 *$ \\
\hline - Constipation & 12 & 20.0 & 6 & 10.0 & 2.6 & 0.008* \\
\hline
\end{tabular}

MH: Marginal homogeneity test for two related samples

$* \mathrm{P}<0.05$ (significant) 
Table (4): Comparison between caloric, protein, carbohydrates and fats intakes at the beginning and at the end of the study $(n=60)$.

\begin{tabular}{|c|c|c|c|c|c|c|c|c|}
\hline \multirow{3}{*}{ Food frequency } & \multicolumn{6}{|c|}{ Study phase } & \multirow{3}{*}{$\mathbf{Z}$} & \multirow{3}{*}{$\mathbf{P}$} \\
\hline & \multicolumn{3}{|c|}{ at beginning } & \multicolumn{3}{|c|}{ at the end } & & \\
\hline & Mean & SD & Median & Mean & SD & Median & & \\
\hline $\begin{array}{l}\text { Energy intake } \\
\text { (kcal) }\end{array}$ & 629.7 & 495.2 & 472.0 & 792.6 & 426.2 & 698.5 & 2.8 & $0.005 *$ \\
\hline protein intake $(\mathrm{g})$ & 29.6 & 25.7 & 26.9 & 41.6 & 28.5 & 32.7 & 3.6 & $0.000 *$ \\
\hline $\begin{array}{l}\text { carbohydrates } \\
\text { intake }(\mathrm{g})\end{array}$ & 80.2 & 66.4 & 58.0 & 110.8 & 70.6 & 70.8 & 2.7 & 0.008* \\
\hline fats intake (g) & 21.9 & 18.5 & 17.4 & 25.8 & 14.4 & 24.7 & 2.1 & $0.035 *$ \\
\hline
\end{tabular}

Z: Wilcoxon test for two related samples

$* \mathrm{P}<0.05$ (significant)

Table (5-a): Comparison of means weight-for-age and height-for-age percentiles of the leukemic adolescents $(n=60)$.

\begin{tabular}{|c|c|c|c|c|c|}
\hline \multirow{2}{*}{ Parameter } & \multicolumn{3}{|c|}{ Study phase } & \multirow{2}{*}{$X^{2}$} & \multirow{2}{*}{$\mathbf{P}$} \\
\hline & Beginning & $\begin{array}{c}\text { After } \\
\text { 2months }\end{array}$ & $\begin{array}{l}\text { At the } \\
\text { End }\end{array}$ & & \\
\hline $\begin{array}{l}\text { Weight-for-age percentile } \\
\text { - Minimum } \\
\text { - Maximum } \\
\text { - Mean } \\
\text { - SD } \\
\text { - Median }\end{array}$ & $\begin{array}{c}2.30 \\
100.00 \\
67.52 \\
24.60 \\
75.80\end{array}$ & $\begin{array}{c}2.90 \\
99.60 \\
71.11 \\
23.81 \\
77.30\end{array}$ & $\begin{array}{c}3.60 \\
99.50 \\
73.16 \\
23.15 \\
75.80\end{array}$ & 37.4 & $0.000 *$ \\
\hline $\begin{array}{l}\text { Height-for-age percentile } \\
\text { - Minimum } \\
\text { - Maximum } \\
\text { - Mean } \\
\text { - SD } \\
\text { - Median }\end{array}$ & $\begin{array}{c}0.00 \\
99.40 \\
35.73 \\
30.25 \\
21.20\end{array}$ & $\begin{array}{c}0.00 \\
99.40 \\
35.73 \\
30.25 \\
21.20\end{array}$ & $\begin{array}{c}0.00 \\
99.40 \\
35.73 \\
30.25 \\
21.20\end{array}$ & 0.0 & 1.000 \\
\hline
\end{tabular}

$\mathrm{X}^{2}$ : Friedman test for repeated measures

$* \mathrm{P}<0.05$ (significant) 
Table (5-b): Comparison of means of BMI, Mid-arm circumference, and Skin fold thickness of the leukemic adolescents $(n=60)$.

\begin{tabular}{|c|c|c|c|c|c|c|c|c|}
\hline \multirow{3}{*}{$\begin{array}{l}\text { Anthropometric } \\
\text { measurements }\end{array}$} & \multicolumn{6}{|c|}{ Study phase } & \multirow{3}{*}{$\mathbf{F}$} & \multirow{3}{*}{$\mathbf{P}$} \\
\hline & \multicolumn{2}{|c|}{ at beginning } & \multicolumn{2}{|c|}{ after 2 months } & \multicolumn{2}{|c|}{ at the end } & & \\
\hline & Mean & SD & Mean & SD & Mean & SD & & \\
\hline BMI $\left(\mathrm{kg} / \mathrm{m}^{2}\right)$ & 24.6 & 3.1 & 25.1 & 3.1 & 25.4 & 3.5 & 16.9 & $0.000 *$ \\
\hline $\begin{array}{l}\text { Mid-arm } \\
\text { circumference }(\mathrm{cm})\end{array}$ & 25.8 & 3.6 & 26.2 & 3.2 & 26.8 & 3.3 & 10.7 & $0.000 *$ \\
\hline $\begin{array}{l}\text { Skin fold thickness } \\
(\mathrm{mm})\end{array}$ & 12.2 & 2.8 & 12.9 & 2.7 & 13.5 & 2.7 & 12.2 & $0.000 *$ \\
\hline
\end{tabular}

Table (6): Comparison between different laboratory investigations throughout the study phases $(\mathbf{n}=60)$.

\begin{tabular}{|c|c|c|c|c|c|c|c|c|}
\hline \multirow{3}{*}{ Lab investigations } & \multicolumn{6}{|c|}{ Study phase } & \multirow{3}{*}{$\mathbf{F}$} & \multirow{3}{*}{$\mathbf{P}$} \\
\hline & \multicolumn{2}{|c|}{ at beginning } & \multicolumn{2}{|c|}{$\begin{array}{l}\text { after } 2 \\
\text { months }\end{array}$} & \multicolumn{2}{|c|}{ at the end } & & \\
\hline & Mean & SD & Mean & SD & Mean & SD & & \\
\hline $\mathrm{Hb}(\mathrm{g} / \mathrm{dl})$ & 8.8 & 2.7 & 9.3 & 1.8 & 9.6 & 1.7 & 6.5 & $0.003 *$ \\
\hline Hct $(\%)$ & 27.8 & 9.6 & 29.5 & 7.6 & 30.7 & 6.2 & 12.1 & $0.000 *$ \\
\hline Serum albumin (g/dl) & 3.0 & 0.7 & 3.1 & 0.4 & 3.1 & 0.4 & 1.8 & 0.172 \\
\hline $\operatorname{WBC}\left(10^{3}\right)$ & 6.6 & 5.6 & 8.7 & 4.5 & 9.0 & 3.0 & 20.3 & $0.000 *$ \\
\hline $\operatorname{RBC}\left(10^{6}\right)$ & 2.8 & 0.6 & 3.0 & 0.6 & 2.9 & 0.4 & 8.8 & $0.000 *$ \\
\hline Serum urea (mg) & 23.3 & 4.5 & 24.8 & 5.5 & 22.9 & 3.9 & 12.9 & $0.000 *$ \\
\hline
\end{tabular}

F: Repeated measures ANOVA

$* \mathrm{P}<0.05$ (significant) 
Table (7): General examination of the studied group at the beginning of the study, after 2 months and at the end of the study $(n=60)$.

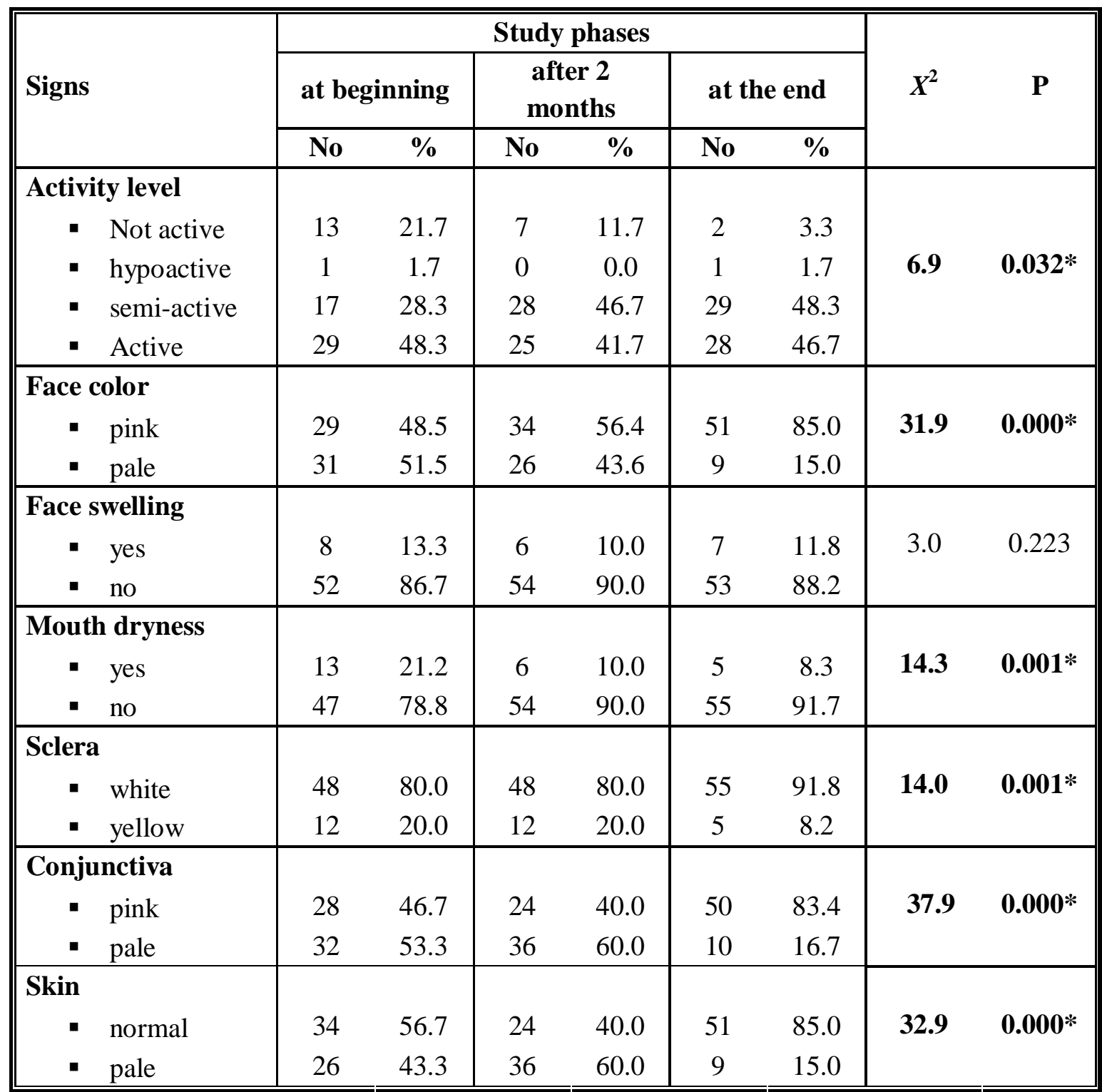

X2: Friedman test for several related samples

$* \mathrm{P}<0.05$ (significant) 


\section{References}

1. Ball $\mathrm{J}$ and Bindler R. Pediatric Nursing: Caring for Children. $4^{\text {th }}$ Edition. New Jersey: Pearson Prentice Hall Publication. 2008.

2. Shaw V, Lawson M. Clinical Pediatric Dietetics. $2^{\text {nd }}$ ed. Iowa: Blackwell Science, 1994: 351.

3. Hamayun M, Afzal-Khan S, Muhammad $\mathrm{W}$. Investigation on the prevalence of leukemia in North West Frontier Province of Pakistan. Turkish Journal of Cancer 2005; 35(3): 119-22.

4. Tadmouri G, Nair P, Obeid T, Gallala S. Genetics Made Easy 2: Cancers. Center for Arab Genomic Studies, 2008: 11.

5. Mosby T, Barr R, Pencharz P. Nutritional Assessment of Children with Cancer. Journal of Pediatric Oncology Nursing 2009; 26(4): 186-97.

6. Suskind R, Suskind L. Textbook of Pediatric Nutrition. $2^{\text {nd }}$ Ed. New York: Raven Press, 1993: 417.

7. Han-Markey T. Nutritional Considerations in Pediatric Oncology. Seminars in Oncology Nursing 2000; 16(2): 146-51.

8. Koen FM, Hulst J. Prevalence of Malnutrition in Pediatrics Hospital Pateints. Current Opinion in Pediatrics 2008; 20(5): 590-6.

9. Kleiman R. Pediatric Nutrition Handbook. $6^{\text {th }}$ Ed. New York: American Academy of Pediatrics, 2009.

10. Davies M. Nutritional Screening and Assessment in Cancer-Associated Malnutrition. European Journal of Oncology Nursing 2005; 9: 64-73.

11. Elia M, Stratton R. On the ESPEN guidelines for nutritional screening 2002. ClinNutr 2004; 23: 131-2.
12. Kondrup J, Allison SP, Elia M, Vellas B, Plauth M. Educational and Clinical Practice Committee, European Society of Parenteral and Enteral Nutrition (ESPEN). ESPEN guidelines for nutrition screening 2002. ClinNutr 2003; 22: 415-21.

13. Hendricks K, Duggan C. Manual of Pediatric Nutrition. Decker, 2005.

14. Members of Royal College of Nursing. Malnutrition: what nurses working with children and young people need to know and do. London: Royal College of Nursing, 2006: 1.

15. American Academy of Pediatrics. Policy Statement: Guidelines for Pediatric Cancer Centers. Pediatrics 2004; 113(6): 1833-5.

16. Cherry L. Nutrition Assessment of the Pediatric Oncology Patients. Oncology Nutrition Connection 2011; 19(2): 4-12.

17. Rybojad P, Dłuski D, Rybojad B, Kędra M, Sawicki M, Skoczylas P, and Tabarkiewicz J. Urban vs. rural patients. Differences in stage and overall survival among patients treated surgically for lung cancer. Annals of Agricultural and Environmental Medicine 2013; 20(1): 101-5.

18. Bevier $\mathrm{M}$, Weires $\mathrm{M}$, Thomsen $\mathrm{H}$, Sundquist $\mathrm{J}$, and Hemminiki $\mathrm{K}$. Influence of family size and Birth Order on Risk of Cancer: A Population-Based Study. Cancer 2011; 11: 163-73.

19. Behren L, Spector L, Mueller B, and Johnson K. Birth Order and Risk of childhood Cancer: A Pooled Analysis from Five US States. Internationa Journal of Cancer 2010; 128: 2709-16.

20. Hornell O, Skolin I, and Wahlin Y. Energy and Nutrient Intake and Nutritional Status of Children with Malignant Disease during Chemotherapy after the Introduction of New Mealtime 
Routine. Scandinavian Journal of Caring Sciences 2012; 15(1): 82-91.

21. Rodgers $\mathrm{C}$ and Walsh T. Nutritonal Issues in Adolescents After Bone Marrow Transplantation: A Literature Review. Journal of Pediatric Oncology Nursing 2008; 25(5): 254-64.

22. Dodd MJ. Efficacy of Proactive Information on Self-Care in Chemotherapy Patients. Patient EducCouns 1988; 11(3): 215-25.

23. Moore J and Beckwitt A. Children with Cancer and their Parents: Self-Care and Dependent-Care Practices. Issues in Comprehensive Pediatric Nursing 2004; 27: 1-17.

24. Hoffman KR. Nutritional Intervention Improves Patient Tolerability of Chemotherapy and/or Radiation Therapy by Preventing Symptomatic Bone Marrow Depression While Improving Local Control of Disease and maintaining a Patient's Performance Status during Therpay. American Society of Clinical Oncology 2002; 2868-73.

25. Park K. Nutrition and Health: Park's Textbook of Prevention and Social Medicine. 20 ${ }^{\text {th }}$ ed. BanarsidasBhanot Publishers, Jabalpur, India. 2009.

26. Linga V, Shreedhara A, and Rau A. Nutritional Assessment of children With hematological malignancies and their Subsequent Tolerance to Chemotherapy. The Ochsner Journal 2012; 12: 197-201.

27. Bond, S. A. Energy Intake and Basal Metabolic Rate during Maintenance Chemotherapy. Arch.Dis.Child 1992; 67(2): 229-32.

28. Owens J, Hanson S, McArthur J, and Mikhailov T. The Need for Evidence Based Nutritional Guidelines for Pediatric Acute Lymphoblastic Leukemia Patients: Acute and Long- term Following Treatment. Nutrients 2013; 5: 4333-46.

29. Reilly J, Brougham M, Gibson B. Effect of Glucocorticoid Therapy on Energy Intake in Children Treated for Acute Lymphoblastic Leukemia. The Journal of Clinical Endocrinology \& Metabolism 2001; 86(8):3742-5.

30. Murphy $T$ and Nieuwoudt C. Nutrition and the Child with Cancer: where do we stand and where do we need to go? South Africa Journal of Clinical Nutrition 2011; 24(3): S23-S6.

31. Jain V, Dubey AP, and Gupta SK. Nutritional Status of Children with Malignancy. Indian Pediatrics 2003; 40(10): 976-84.

32. Ali A, Adam K. Effects of chemotherapy on the levels of plasma urea, uric acid and creatinine as indicators of renal impairment in Sudanese cancer patients. Al Neelain Medical Journal 2013; 3(8): 78-85.

33. Pui C, Mullighan G, Evans W, and Relling M. Pediatric Acute Lymphoblastic Leukemia: where are we going and how do we get there? Blood 2012; 120: 1165-74.

34. Huhmann $\mathrm{H}$ and Cunningham R. Importance of Nutritional Screening in Treatment of Cancer-Related Weight Loss. The Lancet Oncology 2005; 6(5): 334-43.

35. Fuemmeler B, Clark K, and Rosoff P. Diet, Physical Activity, and Body Composition Changes during the First Year of Treatment for Childhood Acute Leukemia and Lymphoma. J PediatrHematolOncol 2013; 35(6): 43743.

36. Yee Tan S, Poh B, Tahir A, Norimah A, and Rahman J. Physical activity of pediatric patients with acute leukemia undergoing induction or consolidation 
chemotherapy. Leukemia Research 2013; 37: 14- 20 .

37. Kauhanen L, Järvelä L, Heinonen O, and Axelin A. Active video games to promote physical activity in children with cancer: a randomized clinical trial with follow-up. BMC Pediatrics 2014; 14:94-104.
38. Florin T, Fryer E, and Miyoshi $T$. Physical Inactivity in Adult Survivors of Childhood Acute Lymphoblastic Leukemia: A Report from the Childhood Cancer Survivor Study. Cancer Epidemiol Biomarkers Prev 2007; 16(7):1356-63. 